\title{
Device Fixation in Cochlear Implant Surgery: Bone Well vs. Subperiosteal Muscle Pocket Technique
}

\author{
Raquel A. Lauria, Gisele M. Truzzi, Alexandre Caixeta Guimarães, Sílvia Badur Curi, \\ Arthut M. Castilho, Jorge Rizzato Paschoal, Walter Adriano Bianchini, \\ Guilherme Machado de Carvalho* \\ Otology, Audiology and Implantable Ear Prostheses Ear, Nose, Throat and Head \& Neck Surgery Department, \\ Campinas University, São Paulo, Brazil \\ Email: otorrino@fcm.unicamp.br, ${ }^{*}$ guimachadocarvalho@gmail.com
}

Received 15 November 2015; accepted 30 November 30; published 4 December 2015

Copyright (C) 2015 by authors and OALib.

This work is licensed under the Creative Commons Attribution International License (CC BY). http://creativecommons.org/licenses/by/4.0/

(c) (i) Open Access

\begin{abstract}
Introduction: Cochlear implantation (CI) is a worldwide procedure that provides hearing rehabilitation and improves speech perception. One of the described complications is the device migration, which can result of failure of receiver-stimulator $(R / S)$ fixation. This study aims to describe the outcomes of cochlear implant receiver-stimulator (RS) placement (bone well and the subperiosteral temporal pocket technique without fixation). Methods: A retrospective case review is developed in tertiary care university hospital center that compares the bone well and the subperiosteral temporal pocket technique without fixation in two periods (at the end of the surgery and one year after CI surgery). Results: The age range from 22 to 64 years (average of 41.2 year-old). Follow-up time ranges from 12 to 51 months (average 24 months). The patients, divided into two groups (subperiostal pocket $=6$ patients and bone well $=3$ patients), are analyzed through major and minor complications. No intraoperative wounds or intracranial complications have been observed in either group. Device migration occurs in three patients of subperiostal pocket group $(50 \%)$, but with no apparent clinical outcomes. The migration measure is about not more than 1 up to 2 centimeters antero-inferiorly by the radiography evaluation. Conclusion: Device migration is more frequent in the subperioteal pocket group (50\%) with statistical significance $(p<0.05)$. However it is not identified, apparently, no clinical and aesthetic account related to this situation.
\end{abstract}

\section{Keywords}

Cochlear Implant, Cochlear Implants Complications, Hearing Loss, Device Migration

\footnotetext{
${ }^{*}$ Corresponding author.
}

How to cite this paper: Lauria, R.A., Truzzi, G.M., Guimarães, A.C., Curi, S.B., Castilho, A.M., Paschoal, J.R., Bianchini, W.A. and de Carvalho, G.M. (2015) Device Fixation in Cochlear Implant Surgery: Bone Well vs. Subperiosteal Muscle Pocket Technique. Open Access Library Journal, 2: e2177. http://dx.doi.org/10.4236/oalib.1102177 


\section{Introduction}

Hearing problems are related to approximately three hundred and sixty million people all over the world, which is close to $5.3 \%$ of all people and it has to be shown that around $9 \%$ of those people are children [1].

Depression, reading problems, cognitive disabilities, social issues and isolation, negative economic involvement factors (individuals and social) may be some problems that people with deafness have to face. And also it needs to be alert that people with hearing have difficulties to work and this population has elevated levels of unemployment [1] [2].

Currently many people with severe hearing loss can be excellent candidates to achieve a hearing rehabilitation, especially subjects with severe/profound bilateral sensorineural hearing loss. The treatment's options are related to some different approaches, like hearing aids (HA) devices, signal language, oralization, lip reading and cochlear implantation (CI) [1] [2].

$\mathrm{CI}$ is a worldwide procedure that provides hearing rehabilitation and improves speech perception [1]-[3].

One of the described complications is the device migration, which can result of failure of receiver-stimulator $(\mathrm{R} / \mathrm{S})$ fixation. With the increase of operative experience and refinement of the procedure, plenty techniques of $\mathrm{R} / \mathrm{S}$ fixation were described in the literature, such as suture fixation, temporal is pocket, drilling a bony seat or well. However, the ideal technique to avoid complications still remains a point of debate [4] [5].

The aim to this short paper is to describe the outcomes of cochlear implant receiver-stimulator (RS) placement (bone well and the subperiosteral temporal pocket technique without fixation) in a retrospective analysis.

\section{Methods}

A retrospective case review was developed in tertiary care university hospital center.

Clinical sample included patients with severe-to-profound hearing loss who underwent cochlear implant surgery between October 2008 and April 2013 using devices from the same manufacturer (Medel).

Those patients were divided into two groups: one with the bone well fixation technique and the other group without device fixation (subperiosteal temporal pocket).

For achieving the migration of the R/S was utilized the radiography examination of the temporal bone in a transorbital approach. The radiography was performed on the immediate post operative time and in the follow up period (more than 1 year of the surgery).

\subsection{Inclusion Criteria}

Inclusion criteria were all patients that underwent to cochlear implant surgery between Oct/2008 to April/2013 with Medel device. The subjects need to have a surgery detailed report to identified the R/S fixation technique and a radiography examination of the temporal bone in a transorbital approach at the immediate post operative time and a control radiography performed at least one year after the surgery.

All patients who did not complete these criteria were excluded from the study.

\subsection{Statistical Analysis}

The data were analyzed using descriptive analysis, with production of means, medians, standard deviation tabs.

Chi-Square was used to compare the groups of our sample. Spearman analysis and Mann-Whitney tests was also performed.

The confidence Interval was of 95\%, and $p$-value $<0.05$ was considered significant.

\subsection{Ethical Considerations}

This study was previously approved by the Research Ethics Committee of the Faculty of Medical Sciences of the Institution and all subjects signed the informed consent form. 


\section{Results}

Thirty-two patients were selected for the study, however twenty trees not reached the inclusion criteria and only nine patients were included in this manuscript.

The age range from 22 to 64 years (average of 41.2 year-old). Follow-up time ranged from 12 to 51 months (average 24 months).

The patients, divided into two groups (subperiostal pocket $=6$ patients and bone well $=3$ patients), were analyzed through major and minor complications. No intraoperative wounds or intracranial complications have been observed in either group.

Device migration occurred in three patients of subperiostal pocket group (50\%). but with no apparent clinical outcomes. The migration measure was about not more than 1 up to 2 centimeters antero-inferiorly by the radiography evaluation.

No migration in bone well fixation group occurred. The three patients with the R/S migration did not have any complain related to the device (functional and aesthetic). None of the patients, of both groups, have any aesthetic complain.

The patient's characteristics are shown in Table 1.

\section{Discussion}

The fixation of cochlear implant device is a discussed topic in literature, with a wide variety of techniques described.

One device fixation method recommended is the creation of a bony well in which the R/S may be recessed. In some cases, exposure of the dura is required and complications such as epidural hematoma, subdural hematoma, temporal lobe infarction and dural tears with cerebrospinal fluid leak can arise, although rare [4]-[6].

In contrast, there are few complications reported in the literature in the subperiosteal pocket technique. In our study, there was no intraoperative or intracranial complications observed in either groups, besides the device migration [4] [5].

In our review, there were no statistically significant differences between both groups regarding overall complications. Regarding the device migration, it was higher in the group undergoing subperiostal pocket technique $(p<0.05)$.

This data has some limitations like the number of the analyzed patients, and for the device migration evaluation. However, it is important to affirm that any patients, in both groups, had complains related to the CI functioning or aesthetics issues related to de CI device or related to the device migration.

\section{Conclusions}

Device migration is more frequent in the subperioteal pocket group (50\%) with statistical significance $(p<0.05)$. However it is not identified, apparently, no clinical and aesthetic account relates to this situation.

Table 1. Subject’s clinical data.

\begin{tabular}{|c|c|c|c|c|c|}
\hline Patient & Gender & Age (years) & Follow-up (months) & Device fixation & Migration \\
\hline 1 & M & 49 & 30 & Bone well & no \\
\hline 2 & M & 29 & 51 & Bone well & no \\
\hline 3 & M & 44 & 27 & Bone well & no \\
\hline 4 & $\mathrm{~F}$ & 64 & 19 & Pocket & no \\
\hline 5 & $\mathrm{~F}$ & 39 & 12 & Pocket & yes \\
\hline 6 & $\mathrm{~F}$ & 50 & 17 & Pocket & yes \\
\hline 7 & M & 24 & 23 & Pocket & no \\
\hline 8 & M & 22 & 24 & Pocket & no \\
\hline 9 & $\mathrm{~F}$ & 50 & 16 & Pocket & yes \\
\hline
\end{tabular}

Obs.: $\mathrm{M}=$ male; $\mathrm{F}$ = female. 
It should be noted that this studied sample is too small. It is essential that further studies with larger samples are important to confirm this suspicion outcome.

\section{Competing Interests}

Nothing to declare. The author(s) declare that they have no competing interests.

\section{Funding}

No funding. Nothing to declare.

\section{References}

[1] Deafness and Hearing loss. World Health Organization. www.who.int/mediacentre/factsheets/fs300/en

[2] Budenz, C.L., Cosetti, M.K., Coelho, D.H., Birenbaum, B., Babb, J., Waltzman, S.B. and Roehm, P.C. (2011) The Effects of Cochlear Implantation on Speech Perception in Older Adults. Journal of the American Geriatrics Society, 59, 446-453. http://dx.doi.org/10.1111/j.1532-5415.2010.03310.x

[3] Pauna, H.F., Carvalho, G.M., Guimarães, A.C., Schuch, L.H., Muranaka, E.B., Bianchini, W.A., Crespo, A.N., Sartorato, E.L. and Castilho, A.M. (2014) Advanced Bionics ${ }^{\circledR}$ Cochlear Implants in Patients with Prelingual Hearing Loss. Otolaryngology, 4, 159.

[4] Sweeney, A.D., Carlson, M.L., Valenzuela, C.V., Wanna, G.B., Rivas, A., Bennett, M.L. and Haynes, D.S. (2015) 228 Cases of Cochlear Implant Receiver-Stimulator Placement in a Tight Subperiosteal Pocket without Fixation. Otolaryngology - Head and Neck Surgery, 152, 712-717. http://dx.doi.org/10.1177/0194599814567111

[5] Gheorghe, D.C. and Zamfir-Chiru-Anton, A. (2015) Complications in Cochlear Implant Surgery. Journal of Medicine and Life, 8, 329-332.

[6] Guimarães, A.C., Carvalho, G.M., Duarte, A.S., Bianchini, W.A., Sarasty, A.B., Gregorio, M.F., Zernotti, M.E., Sartorato, E.L. and Castilho, A.M. (2015) Hearing Preservation and Cochlear Implants According to Inner Ear Approach: Multicentric Evaluation. Brazilian Journal of Otorhinolaryngology, 81, 190-196. http://dx.doi.org/10.1016/j.bjorl.2014.12.002

\section{Abbreviations}

$\mathrm{CI}$ = Cochlear Implant; HA = Hearing Aids; R/S = cochlear implant receiver-stimulator. 